\title{
Identification and Expression of Cathepsin B from Yellow Catfish (Pelteobagrusfulvidraco) in Response to Bacteria and Poly (I:C)
}

\author{
Wang Yun ${ }^{1,3}$, Wang Feijie ${ }^{3}$, Yang Zupeng ${ }^{3}$, Liu Heli ${ }^{3}$, Zhang Yujie ${ }^{3}$, Zhu Xiangzhi $^{2, *}$ \\ ${ }^{1}$ Jianghan University, Institute of Environment and Health, Hubei Key Laboratory of Environmental and Health Effects \\ of Persistent Toxic Substances, Hubei Province, Wuhan, 430056, China. \\ ${ }^{2}$ Hubei University of Chinese Medicine, School of Laboratory Medicine, Hubei Province, Wuhan, 430065, China. \\ ${ }^{3}$ Henan University of Urban Construction, Henan Province Key Laboratory of Water Pollution Control and \\ Rehabilitation Technology, Henan Province, Pingdingshan, 467036, China.
}

\section{Article History}

Received 25 November 2019

Accepted 16 November 2020

First Online 19 November 2020

Corresponding Author

Tel.: +8618627990659

E-mail: zxz2004@hotmail.com

\section{Keywords}

Aeromonas hydrophila

Cathepsin B

Immune response

Poly (I:C)

Yellow catfish

\begin{abstract}
Cathepsin B, a major lysosomal cysteine protease of the papain-like superfamily, plays an important role in host immune response. To study the immune response of yellow catfish (Pelteobagrus fulvidraco) to pathogens, a 1297- bp cDNA of cathepsin B (PfCTSB) from yellow catfish was cloned. It contained a 993-bp ORF flanked by a 25 bp $5^{\prime}$-untranslated region (UTR) and a 279- bp 3'-UTR. The ORF encoded a $36.1 \mathrm{kDa}$ cysteine protease with its deduced amino acid sharing a $90 \%$ sequence identity with that of Ictalurus punctatus. Besides, the predicted PfCTSB was a precursor, including a signal peptide, a propeptide, and a mature peptide. The mature peptide was predicted to be both an endopeptidase based on a catalytic triad (Cys107, His277 and Asn297) and an exopeptidase based on an occluding loop. Furthermore, PfCTSB mRNA was constitutively expressed in all examined tissues, with the highest level seen in liver. Yellow catfish were then injected with inactivated Aeromonas hydrophilaor poly (I:C), and PfCTSB mRNA remarkably increased in the liver, spleen and head kidney when compared with the PBS control. It can be speculated that the identified cathepsin B from yellow catfish was involved in host d-efense against infection.
\end{abstract}

\section{Introduction}

Cathepsin B is a major lysosomal cysteine protease belonging to the $\mathrm{C} 1$ family of papain-like superfamily (Turk et al., 2012). Its cysteine protease activity is exerted by a catalytic triad (Cys, His and Asn) (Turk et al., 2012). Besides, cathepsin B also acts as an exopeptidase (dipeptidyl-carboxypeptidase). This activity is catalyzed by a 20-residue occluding loop (Illy et al., 1997), mainly through two sequential histidines within the loop (Musil et al., 1991; Krupa et al., 2002).

It is inactive when cathepsin B is first synthesized as a prepro cathepsin, including a signal peptide, a propeptide, and a mature peptide, since the propeptide physically blocks the active sites of the mature peptide (Turk et al., 2000). After the signal peptide being hydrolyzed, the remaining procathepsin is modified with a mannose-6-phosphate tag. This tag is then recognized by a lysosome receptor. After translocation to the lysosome, the acidic environment facilitates the excision of the pro-domain by an autocatalytic mechanism or by other proteases, thus resulting in the release of the active mature peptidase. So, a slightly acidic $\mathrm{pH}$ is optimal for the activity of cathepsin B, as identified in that of Cynoglossus semilaevis (Chen \& Sun, 2012), Pseudosciaena crocea (Li et al., 2014), and Scophthalmus maximus (Zhou et al., 2015b).

Cathepsin B plays not only physiological function in intracellular protein turnover and extracellular matrix degration (Cavallo-Medved et al., 2009), but also pathological mechanism in Alzheimer's disease (Hook et al., 2014; Na et al., 2016), rheumatoid arthritis (Trabandt et al., 1991; Hashimoto et al., 2001) and cancer (Aggarwal \& Sloane, 2014). Besides, it is also 
necessary for the host immune response to pathogens. For instance, cathepsin B of Paralichthys olivaceusis induced in response to virus and LPS (Zhang et al., 2008), and is one of the dominant lysosomal proteases in the immune system against Gram-positive $\left(\mathrm{G}^{+}\right.$) bacteria (Cha et al., 2012). Cathepsin B of Epinephelus coioides plays a functional role in Singapore Grouper Iridovirus (SGIV) infection (Wei et al., 2014). Cathepsin B of Oplegnathus fasciatus is involved in the immune response to Gramnegative ( $G^{-}$) bacteria (Whang et al., 2011). Cathepsin B (ctsba) of $I$. punctatus is important for mucosal immunity (Li et al., 2015). These results indicate that cathepsin B is necessary when fishes encounter bacteria or virus infection.

Yellow catfish, an important commercial fish in China, often suffers bacteria or virus infection in summer due to intensive culture, leading to huge loss annually (Zhou et al., 2015a; Wang et al., 2016a). So far, most studies of yellow catfish focus on its feeding (Dan et al., 2013), development (Jing et al., 2014), and pathogen isolation (Ke et al., 2010). Little is known about its immune response to bacteria or virus. So, a full-length cDNA of cathepsin B from yellow catfish was cloned. Its expression in the healthy and challenged specimen was analyzed.

\section{Materials and Methods}

In all assays, yellow catfish, weighting about $100 \mathrm{~g}$, were obtained from the Pingxi Lake in Pingdingshan city, China. They were maintained in a 500-L tank with aeration and filtration systems at $25^{\circ} \mathrm{C}$ for 2 weeks. The fishes were fed with commercial pellets twice a day at a $2 \%$ feeding rate. The water within the tank was half refreshed daily. The "Guidelines for Ethical Conduct in the Care and Use of Nonhuman Animals in Research" were followed when the fishes were sacrificed.

The A. hydrophila (GIM1.172) was obtained from the Guangdong Microbiology Culture Center, cultured in $\mathrm{LB}$ medium at $28^{\circ} \mathrm{C}$, and inactivated by using formalin (Wang et al., 2016b).

The 5 '-end cDNA sequence of PfCTSB was obtained by sequencing a cDNA library of yellow catfish constructed by our laboratory (Ke et al., 2015). Its 3'-end sequence was amplified by $3^{\prime}$-RACE with the following primers (CTSB-3': 5'-CACTATGGAAAACAAGCCTACAGTG3', CTSB-3'-1: 5'-CATCTGATGAGA AGCAGATCATG-3') as previously described (Ke et al., 2015).The ORF was analyzed by software DNA star. Its deduced amino acid sequence was identified by BLASTp (http://blast.ncbi.nlm.nih.gov/Blast.cgi) and aligned with its homologues by ClustalW. Based on alignment, a phylogenic tree was constructed by using neighborjoining algorithm with a bootstrap of 1,000 in MEGA 6.0. Signal peptide and conserved domains of PFCTSB were

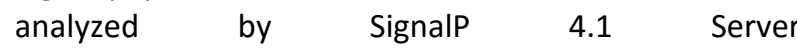
(http://www.cbs.dtu.dk/services/SignalP) and the SMART (http://smart.embl-heidelberg.de). The N- glycosylation sites were predicted by NetNglyc 1.0 Server (http://www.cbs.dtu.dk/ services/NetNGlyc).

To analyze the tissue distribution of PfCTSB mRNA in the yellow fish, eleven kinds of tissues (trunk kidney, intestine, blood, spleen, muscle, skin, liver, head kidney, fin, gill and heart) were collected from the healthy specimen $(n=3)$. Then, total RNA was extracted and transcribed into cDNA (Wang et al., 2016a). Last, the CDNA was used as template to detect the PfCTSB expression via quantitative $P C R$ ( $q P C R$ ) by using the specific primers (qCTSB-F: 5' TGTGACAAACAATGCGAACCC-3', qCTSB-R: ${ }^{\prime}$ 'TGTGACAAACAATGCGAACCC- $3^{\prime}$ ). The 18S rRNA was served as a reference gene (q18S-F: 5'GGACACGGAAAGGATTG ACAGA-3', q18S-R: 5'GTTCGCTATCGGAATTAACCAGA-3'). The relative fold was calculated with $2^{-\triangle \Delta C T}$ method.

To detect the temporal expression of PfCTSB post challenge, the healthy fish were intraperitoneally injected with 200- $\mu$ I PBS (control), or inactivated A. hydrophila $\left(1 \times 10^{7}\right.$ cells $\left./ \mathrm{ml}\right)$, or poly $(\mathrm{l}: \mathrm{C})(1 \mu \mathrm{g} / \mu \mathrm{l}$, Sigma-Aldrich). After injection, the liver, spleen and head kidney were collected at $0,6,12,24,72,120$, or $168 \mathrm{~h}$ from the control and the treated groups $(\mathrm{n}=3)$. The PfCTSB expression was quantified via qPCR. The significance between samples was determined by performing an ANOVA in SPSS 19.0, with significance defined as $\left({ }^{*} \mathrm{P}<0.05\right.$, or $\left.{ }^{*} \mathrm{P}<0.01\right)$.

\section{Results}

The obtained 1297-bp PfCTSB cDNA contained a 25-bp 5'-UTR, a 993-bp ORF, and a 279-bp 3'-UTR with a polyadenylation signal-AATAAA located 18-bp upstream of the 21-bp poly(A) tail (GenBank accession number: KX914677). The ORF encoded a 330-aa precursor with a predicted molecular mass of $36.1 \mathrm{kDa}$ and a theoretical is oelectric point of 5.80. This precursor contained a signal peptide (1-18aa), a propeptide (19-78aa), and a mature peptide (79-330 aa) (Figure 1). Acatalytic triad (Cys107, His277 and Asn297) and an oxyanion hole Gln101 are located in the mature peptide. Besides, a segment of "occluding loop" of cathepsin B family is also situated in the mature peptide, which endows PfCTSB with the unique dipeptidyl-carboxypeptidase activity. Two putative $\mathrm{N}$-glycosylation sites were predicted in Asn37 and Asn190 of PfCTSB (Figure 1). The Asn37 and Asn190 are separately situated in the propeptide and the occluding loop.

The deduced PfCTSB amino acid sequence showed the highest identity $90 \%$ with that of the $I$. punctatus (Figure 1). It also demonstrated 69-84\% identities with cathepsin B of other fishes, mammals, avifauna, and amphibians. The phylogenic analysis also showed that PfCTSB falls into the cathepsin B family with high bootstrap values in branching nodes (Figure 2). In detail, the cathepsin B family are divided into two clusters: one for the fishes, and the other for the mammals, avifauna 


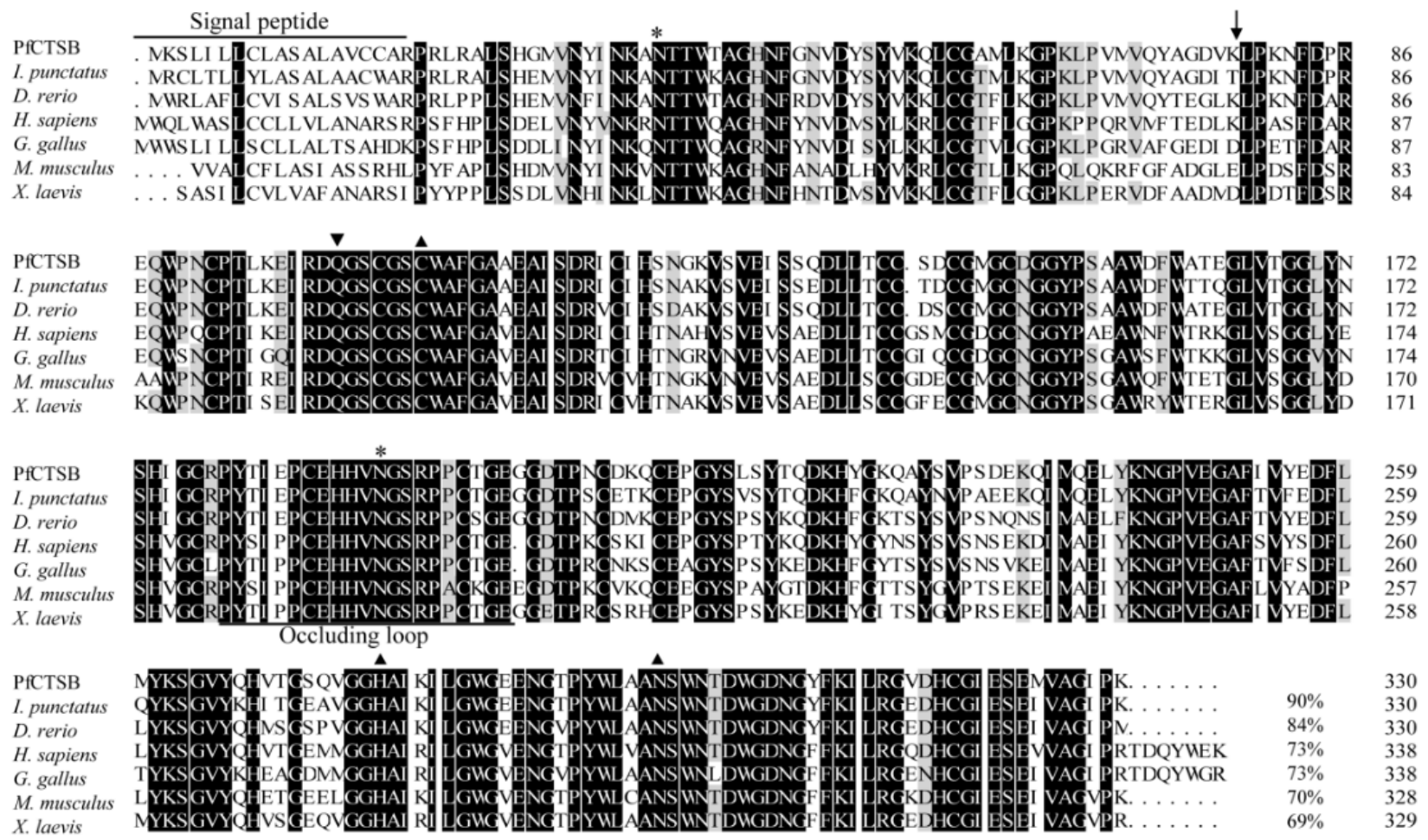

Figure 1. Alignment of the deduced PfCTSB amino acid sequence with its homologues from other species. Their sequence identities with PfCTSB are presented in the bottom right. Dots (.) denote gaps introduced for maximum matching. Consensus sequences are shaded dark; and residues identities $\geqq 75 \%$ are shade gray. The signal peptide is marked with overline. The propeptide and the mature peptide are divided by using an arrow. Residues of the catalytic triad (Cys107, His277, and Asn297) and the oxyanion GIn101 are showed with equilateral triangles and inverted triangle. Two N-glycosylation sites (Asn37 and Asn190) are indicated with asterisks (*). GenBank accession numbers of the aligned sequences are as follows: I. punctatus, JT419332; D. rerio, NP_998501.1; H. sapiens, NP_001899.1; G. gallus, NP_990702.2; M. musculus, NP_031824.1; X. laevis, NP_001079570.

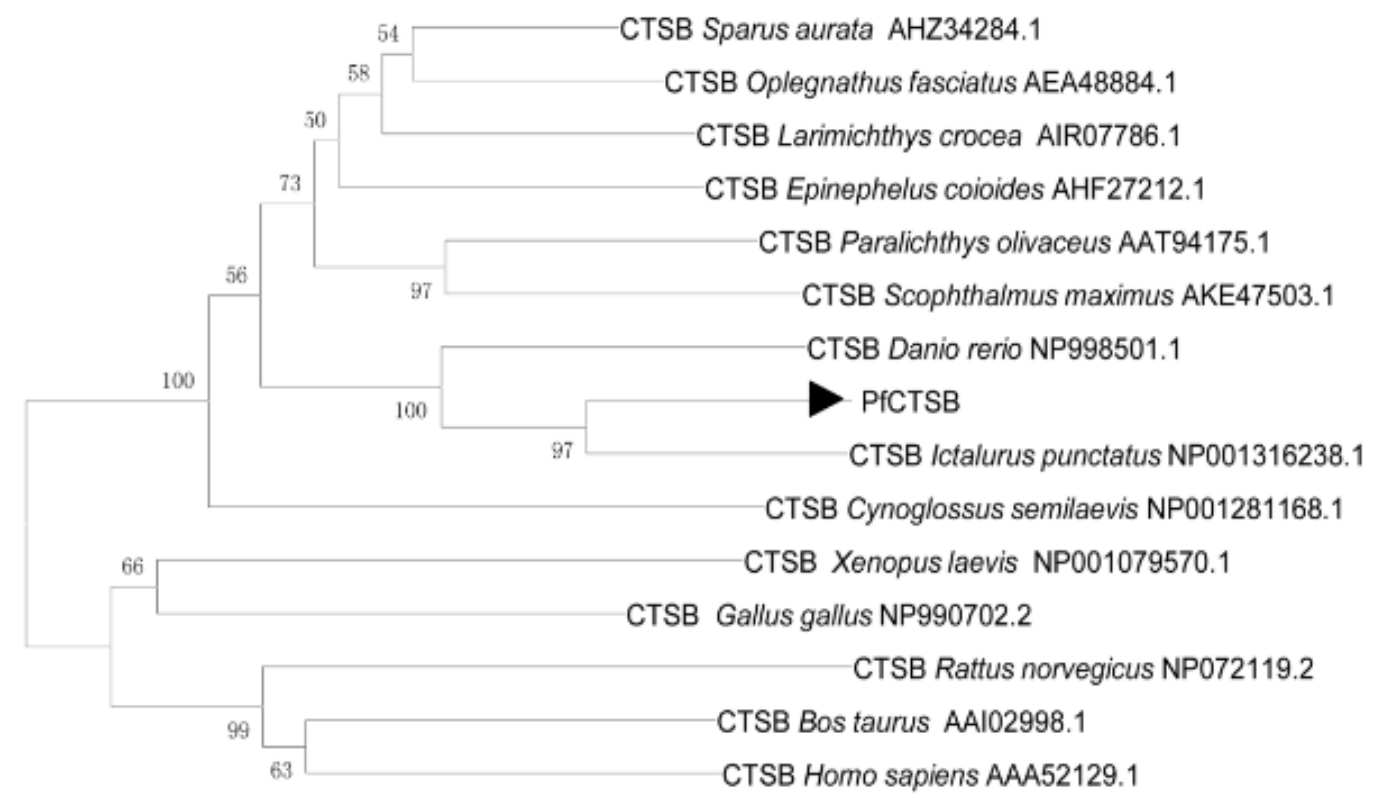

0. 02

Figure 2. Phylogenic analysis of the deduced PfCTSB amino acid sequence and its homologues. Sequences were aligned by ClustalW, and a phylogenic tree was constructed by using a neighbor-joining algorithm with a bootstrap of 1,000 based on MEGA6.0. The bar (0.02) represents the genetic distance. 
and amphibians. PfCTSB groups most closely with that of $I$. punctatus among the fishes.

The PfCTSB mRNA was quantified via qPCR, with 11 tissue types from healthy fish examined and normalized to the blood level (Figure 3). PfCTSB was ubiquitously expressed in all examined tissues. The highest expression level was seen in liver (5.9-fold > blood).

The PfCTSB expression patterns were also checked in liver, spleen and head kidney after inactivated $A$. hydrophila stimuli by running qPCR (Figure 4). PfCTSB mRNA remarkably increased in the three tested tissues compared with the control. PfCTSB mRNA in the liver and head kidney begins to elevate at $6 \mathrm{~h}$ and reaches the highest level at $12 \mathrm{~h}$ (Figure 4a and Figure 4c). Differently, PfCTSB mRNA in the spleen shows no difference from the control until the $7 \mathrm{~d}$ (Figure $4 \mathrm{~b}$ ).

Cathepsin B was involved in not only the antibacterial response, but also the antiviral response. PfCTSB mRNA remarkably accumulated in three examined tissues after poly (I:C) injection (Figure 5 ). Moreover, PfCTSB mRNA has significantly increased at the early $6 \mathrm{~h}$ in the three tested tissues.

\section{Discussion}

Cysteine proteases are the major proteases of the lysosome. They all have conserved Cys, His, Asn and GIn in their active sites (Lecaille et al., 2002). These four key amino acids are also found in the PfCTSB. Any amino acid mutation of the active sites can cause a dramatical reduction in activity (Chen \& Sun, 2012). Like its homologues, PfCTSB shares a typical architecture: a Nterminal signal peptide, a middle propeptide, and a Cterminal mature peptide of a papain family. In addition, the segment of "occluding loop" located in the mature peptide is also conserved among different species, which endows PfCTSB with dipeptidyl-carboxy peptidase activity and is used to identify the enzyme previously (Illy et al., 1997; Eykelbosh \& Van Der Kraak, 2010).

Besides its typical architecture, the amino acid sequence of cathepsin $B$ is also highly conserved among different species. The PfCTSB amino acid sequence showed the highest identity $90 \%$ with that of the $I$. punctatus, which suggests their evolutional relationship. This result is consistent with our previous study (Wang et al., 2016b, 2017). PfCTSB also shared 69-84\% identities with cathepsin Bs of fishes, amphibians and mammals. Such high degree of amino-acid-sequence identity hints its fundamental function in physiological process.

Cathepsin B also play an important role in the host immune system. To study the function of PfCTSB, its expression in different tissues was first quantified via qPCR. Its mRNA was distributed in all tested tissues, thus indicating its multifunctionality. Cathepsins $B$ and $L$ can destroy the network structure of silver carp surimigels, leading to gel softening (Liu et al., 2008). In gentamicininduced acute kidney injury in rats, the amount of cathepsin B decrease along the increased severity of the histopathological lesions of the proximal convoluted tubules, and increase in the well preserved proximal straight tubules (Svara et al., 2010). In human hearts, cathepsin B is expressed and linked to myocardial infarction, the deficiency of which can attenuate cardiac remodeling in response to pressure overload (Wu et al., 2015). Recombinant Trichinella spiralis cathepsin B-like protein can promote STAT6-dependent M1 to M2

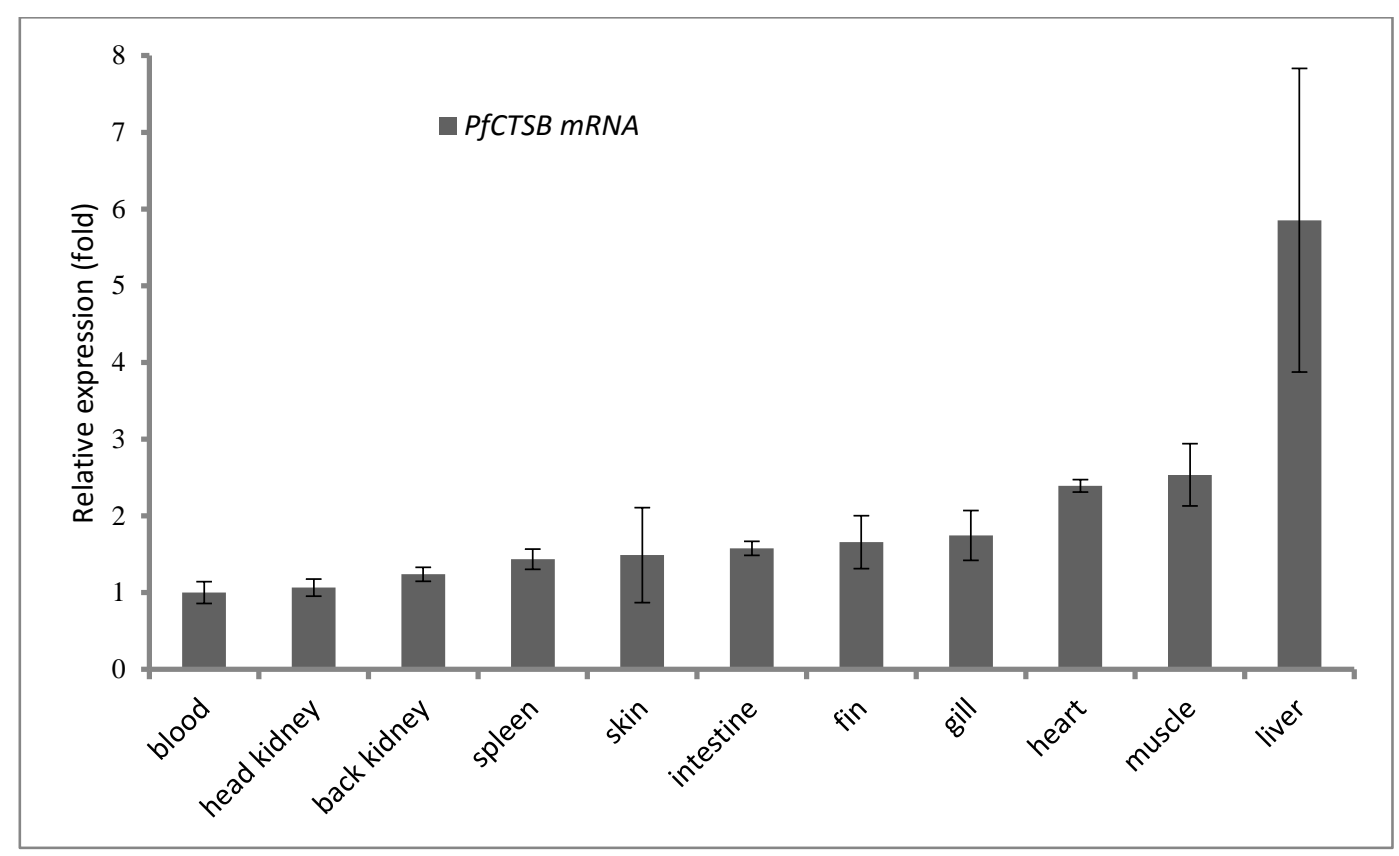

Figure 3. Quantification of the relative expression of PfCTSB mRNA in 11 tissues from healthy yellow catfish via quantitative PCR. The $18 \mathrm{~S}$ rRNA was served as a reference gene, and samples were calibrated against the blood. The relative fold change was calculated with $2^{-\Delta \Delta C T}$ method. 
a

Liver

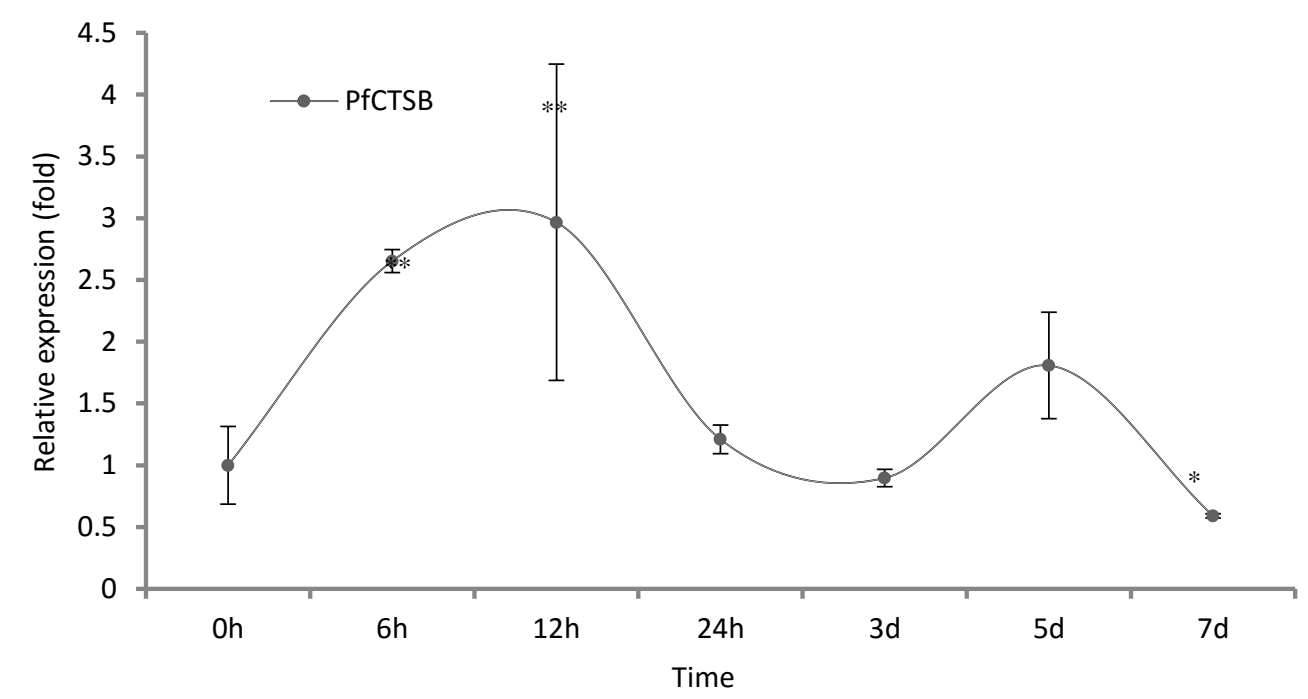

b

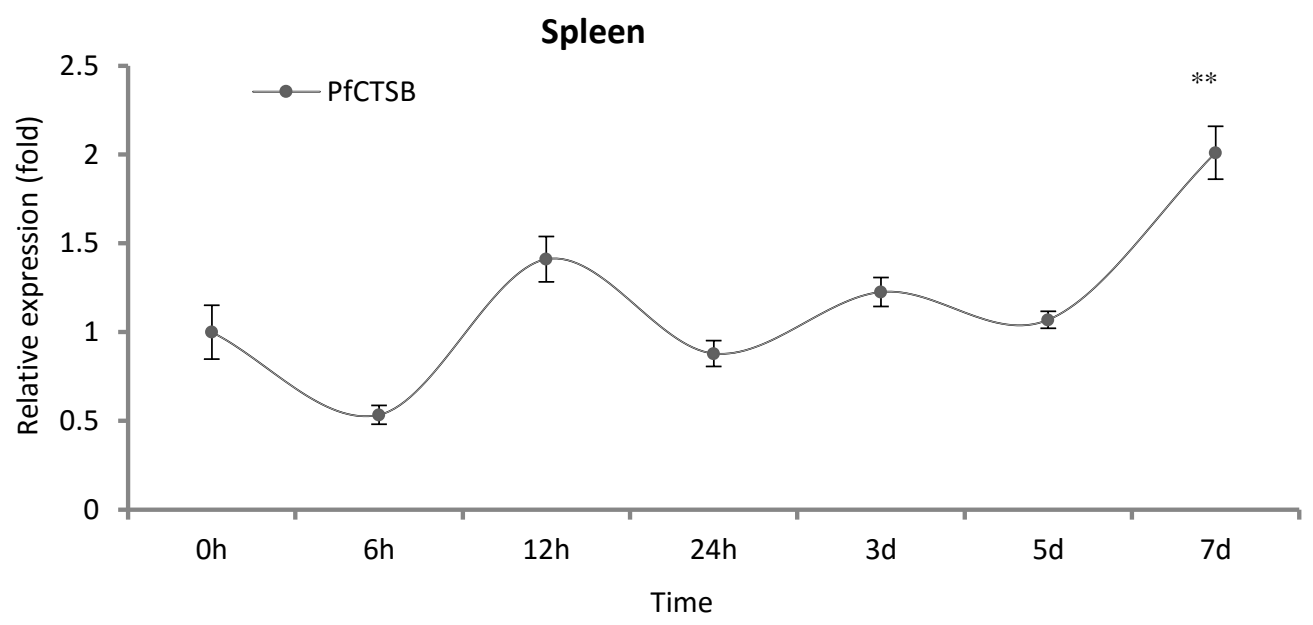

C Head kidney

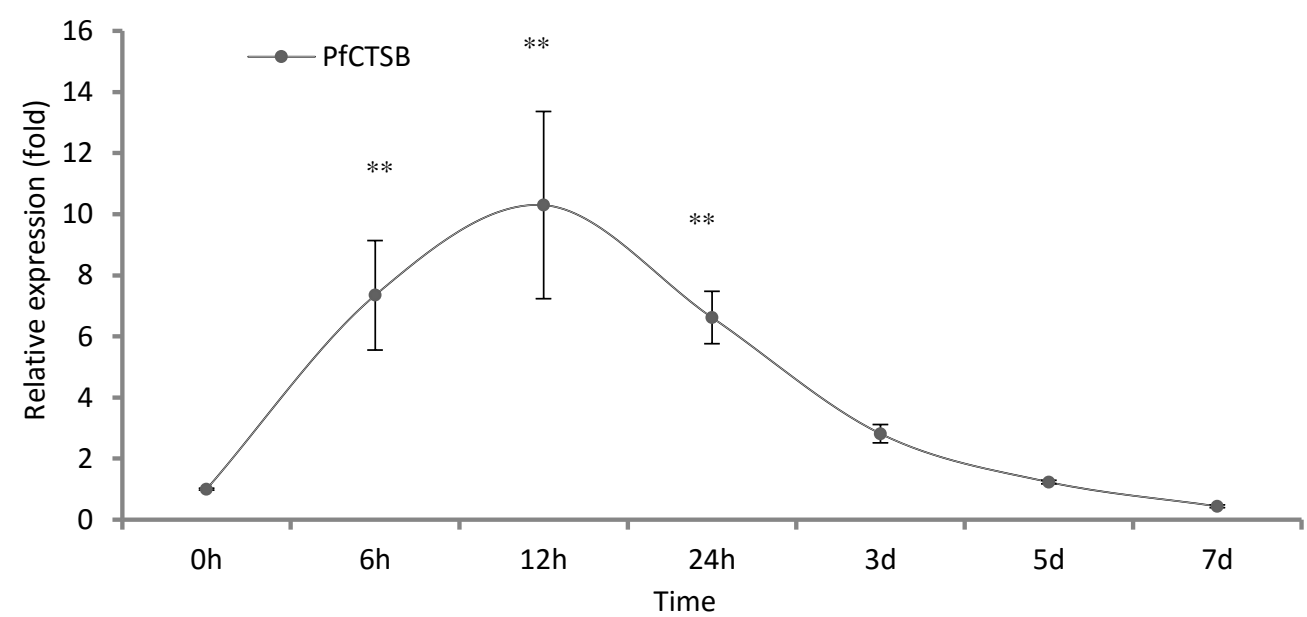

Figure 4. The temporal expression of PfCTSB mRNA in liver (a), spleen (b), and head kidney (c) post bacteria injection compared with the PBS control. The healthy fishes were injected with $200-\mu$ inactivated $A$. hydrophila suspended in PBS $\left(1 \times 10^{7}\right.$ cells $\left./ \mathrm{ml}\right)$ or PBS (control). The PfCTSB mRNA were quantified via qPCR, with the $18 S$ rRNA employed as an internal reference. Values were from three replicates and expressed as a mean $\pm S D ;{ }^{*} P<0.05,{ }^{*} P<0.01$. 
a

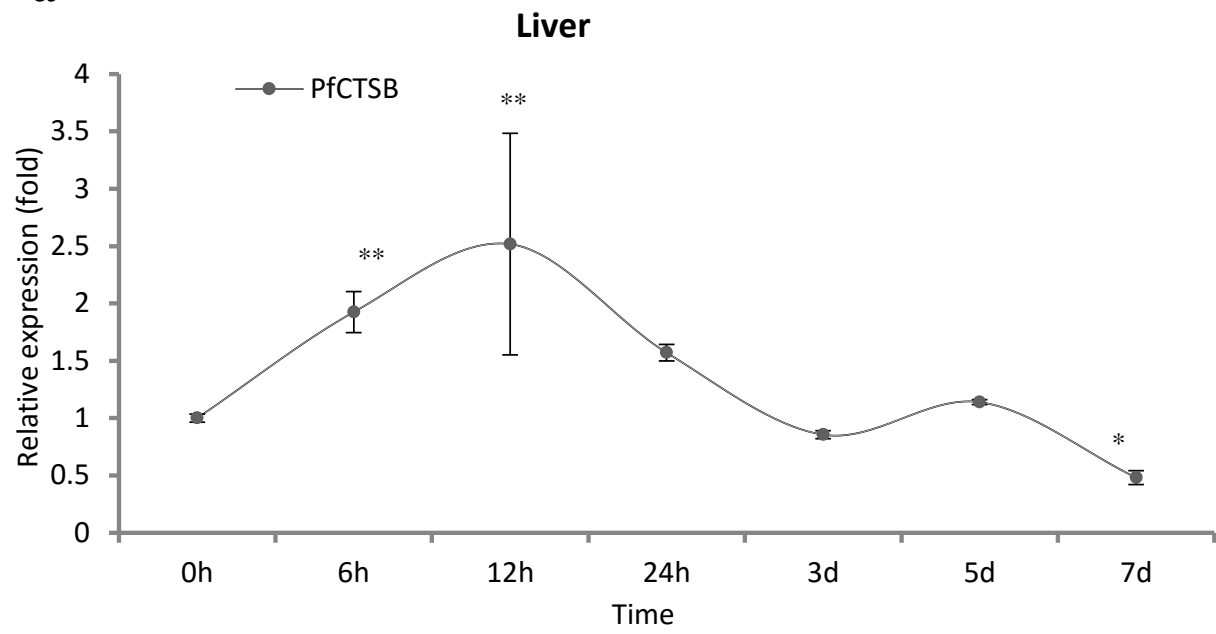

b

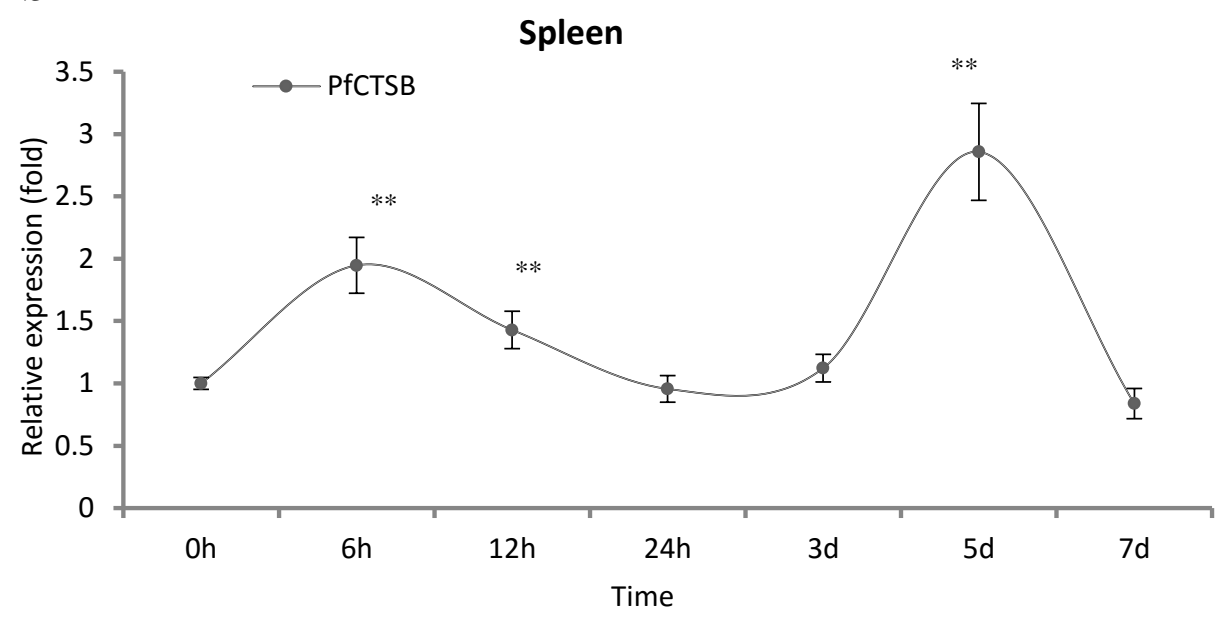

C

Head kidney

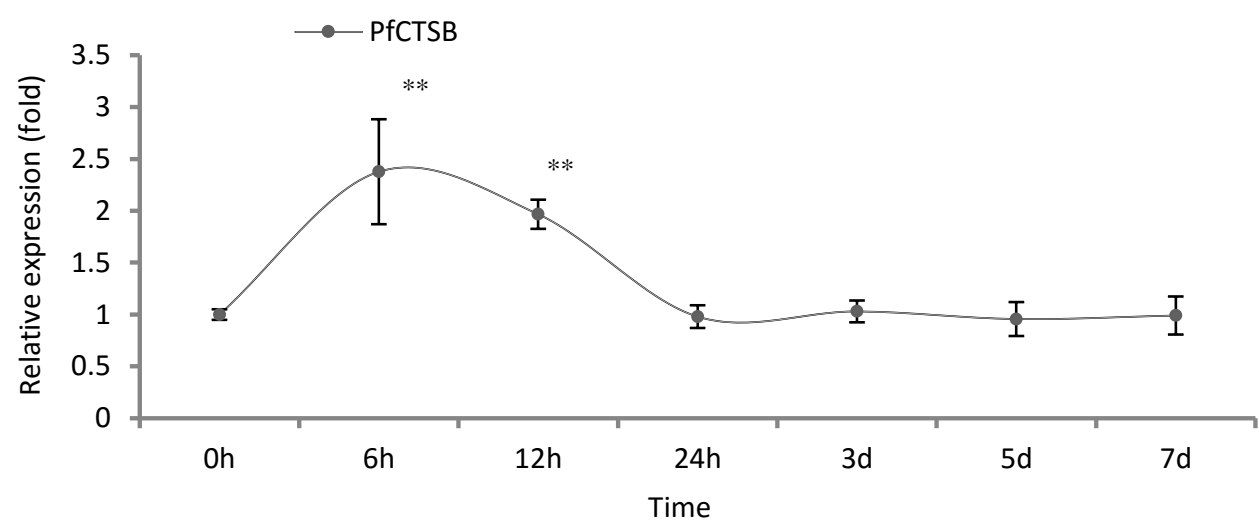

Figure 5. The temporal expression of PfCTSB mRNA in liver (a), spleen (b), and head kidney (c) post poly (I:C) injection relative to the PBS control. The healthy fishes were injected with 200 - $\mu$ lpoly $(\mathrm{I}: \mathrm{C})$ suspended in PBS $(1 \mu \mathrm{g} / \mu \mathrm{l})$ or PBS (control). PfCTSB relative expression levels were detected by using qPCR. The 18S rRNA was served as a housekeeping gene. Values were from three replicates and expressed as a mean $\pm S D ;{ }^{*} P<0.05,{ }^{* * P}<0.01$ 
transition, thus ameliorates intestinal injury (Liu et al., 2015). Increased liver CatB expression in the nonalcoholic steatohepatitis mice, and CatB deficiency can ameliorate liver lipid deposition, inflammatory cell infiltration, and fibrosis (Fang et al., 2020).

The highest expression level was seen in liver (5.9fold > blood), analogous to the RbCathepsin $B$ from Oplegnathus fasciatus (Whang et al., 2011). Since liver is an important immune organ for yellow catfish (Patman, 2014), the highest expression level of PfCTSB in liver suggests its importance in the immune system. Differently, the LycCatB (Li et al., 2014) and SmCatB (Zhou et al., 2015b) are abundant in spleen. FC-CB (Li et al., 2013) and PCCTSB (Dai et al., 2016) are highly expressed in hepatopancreas. The ctsba is abundant in trunk kidney (Li et al., 2015). Cathepsin B of Miiuy croaker is mainly distributed in intestine (Che et al., 2014). These studies present that cathepsin B may be specific in tissue distribution in different species.

Further study revealed that the PfCTSB mRNA was remarkably increased in liver, spleen and head kidney, when the healthy fish were injected within activated $A$. hydrophila, Liver, spleen and head kidney are important immune organs of fish, so the elevated PfCTSB mRNA may be helpful in fending off infection (Cha et al., 2012; Li et al., 2015). The same induction was seen in CsCatB expression by bacterial infection (Chen \& Sun, 2012). Analogously, PCCTSB expression in the hepatopancreas was induced following LPS stimuli (Dai et al., 2016). The cathepsin B gene in the kidney of olive flounder is significantly upregulated at the early stage when fish body was infected $\mathrm{G}^{+}$S. parauberis (Cha et al., 2012). These results indicate that cathepsin $B$ in fish could be induced by $\mathrm{G}^{+}, \mathrm{G}^{-}$bacteria and their pathogenic agent, LPS. However, the temporal expression patterns of PfCTSB in different tissues are divergent. The PfCTSB mRNA in the liver increased within the early $12 \mathrm{~h}$ and decreased in the $7 \mathrm{~d}$. The PfCTSB mRNA in the spleen only remarkably responded in the later period. The PfCTSB mRNA in the head kidney significantly elevated within the $24 \mathrm{~h}$. These results indicated that PfCTSB may work in different ways in different organs. Moreover, LycCatB also participates in processing MHC class IIassociated invariant (li) chain, which is necessary for antigen presentation to $\mathrm{CD}^{+}{ }^{+} \mathrm{T}$-cells, suggesting its importance in adaptive immunity (Li et al., 2014). To detect whether PFCTSB could process li chain, we had overexpressed PfCTSB in E. coli, however, resulting in inclusion body. Further study is needed to obtain the active protease.

Cathepsin B also plays an important role in the antiviral response. PfCTSB mRNA remarkably accumulated in liver, spleen and head kidney after poly $(\mathrm{I}: \mathrm{C})$ injection. Poly $(\mathrm{I}: \mathrm{C})$ is a synthetic analog of double strand RNA (dsRNA), which is produced by most viruses during their replication (Norval, 2012). So, the accumulation of PfCTSB mRNA suggested that it might be involved in viral infection (Zhang et al., 2008; Wei et al., 2014). Moreover, PfCTSB mRNA significantly increased at early $6 \mathrm{~h}$ in the three tested tissues post stimuli. Similarly, PcCatB mRNA remarkably goes up at 0.5 or $1 \mathrm{~h}$ after poly (I:C) challenge (Zhang et al., 2008). These results suggest that cathepsin $B$ may respond in the acute stage of virus infection.

Cathepsin B was also involved in the antiviral response of yellow catfish. PFCTSB MRNA remarkably accumulated in liver, spleen and head kidney after poly $(\mathrm{I}: \mathrm{C})$ injection. Poly $(\mathrm{I}: \mathrm{C})$, long strands of inosine poly $(\mathrm{I})$ homopolymer annealed to strands of cytidinepoly(C) homopolymer, is a synthetic analog of double strand RNA (dsRNA) which is produced by most viruses during their replication (Norval, 2012). Therefore, it is usually used to model the actions of extracellular dsRNA of infected virus, and the increase of PFCTSB mRNA after stimuli suggested its involvement in viral infection (Zhang et al., 2008; Wei et al., 2014). Moreover, PfCTSB mRNA accumulated as early as $6 \mathrm{~h}$ after injection in all three examined tissues. Similarly, PcCatB mRNA remarkably goes up at 0.5 or $1 \mathrm{~h}$ after poly $(\mathrm{I}: \mathrm{C})$ challenge (Zhang et al., 2008). These results suggest that cathepsin $B$ may respond at the early stage of virus infection.

\section{Acknowledgments}

This work was supported by the grant from the National Natural Science Foundation of China (31702388), and by the "Youth Project" of Xiangzhi Zhu of Hubei University of Chinese Medicine (2019ZZX018).

\section{References}

Aggarwal, N., \& Sloane, B.F. (2014). Cathepsin B: multiple roles in cancer. Proteomics Clinical Applications, 8 (5-6), , 427-437. https://doi.org/10.1002/prca.201300105

Cavallo-Medved, D., Rudy, D., Blum, G., Bogyo, M., Caglic, D., \& Sloane, B.F. (2009). Live-cell imaging demonstrates extracellular matrix degradation in association with active cathepsin B in caveolae of endothelial cells during tube formation. Experimental Cell Research, 315(7), 1234-1246.

https://doi.org/10.1016/j.yexcr.2009.01.021

Cha, I.S., Kwon, J., Mun, J.Y.,Park, S.B., Jang, H.B., del Castillo, C.S., Hikima, J., Aoki, T., \& Jung, T.S. (2012). Cathepsins in the kidney of olive flounder, Paralichthys olivaceus, and their responses to bacterial infection. Developmental And Comparative Immunology, 38(4), 538-544. https://doi.org/10.1016/j.dci.2012.08.005

Che, R., Sun, Y., Sun, D., \& Xu, T. (2014). Characterization of the miiuy croaker (Miichthys miiuy) transcriptome and development of immune-relevant genes and molecular markers. PLoS One, 9, e94046. https://doi.org/10.1371/journal.pone.0094046

Chen, H., Lv, M., Lv, Z., Li, C., Xu, W., Zhang, W., Zhao, X.L., Duan, X.M., \& Jin, C.(2017). Molecular cloning and functional characterization of cathepsin B from the sea cucumber Apostichopus japonicus. Fish Shellfish Immunology, 60, , 447-457. https://doi.org/10.1016/j.fsi.2016.11.033

Chen, L., \& Sun, L. (2012). Cathepsin B of Cynoglossus semilaevis: identification, expression, and activity analysis. Comparative Biochemistry and Physiology B- 
biochemistry \& Molecular Biology, 161(1), , 54-59. https://doi.org/10.1016/j.cbpb.2011.09.008

Dai, L.S., Sun, Y., Sun, Y.X., Zhu, B.J., \& Liu, C.L. (2016). Characterization and function of a cathepsin $B$ in red crayfish (Procambarus clarkii) following lipopolysaccharide challenge. Fish \& Shellfish Immunology, 56,,162-168. https://doi.org/10.1016/j.fsi.2016.07.016

Dan, C., Mei, J., Wang, D., \& Gui, J.F. (2013). Genetic differentiation and efficient sex-specific marker development of a pair of $\mathrm{Y}$ - and $\mathrm{X}$-linked markers in yellow catfish. International Journal of Biological Sciences, 9(10), 1043-1049. https://doi.org/10.7150/ijbs.7203

Eykelbosh, A.J., \& Van Der Kraak, G. (2010). A role for the lysosomal protease cathepsin B in zebrafish follicular apoptosis. Comparative Biochemistry and Physiology Part A: Molecular and Integrative Physiology. 156(2), 218-223. https://doi.org/10.1016/j.cbpa.2010.02.005

Fang, W.Q., Deng, Z.Y., Benadjaoud, F., Yang, C.Z., \& Shi, G.P.(2020). Cathepsin B deficiency ameliorates liver lipid deposition, inflammatory cell infiltration, and fibrosis after diet-induced nonalcoholic steatohepatitis. Translational Research, 222, 28-40. https://doi.org/10.1016/j.trsl.2020.04.011

Gwon, S.H., Kim, H.K., Baek, H.J., Lee, Y.D., \& Kwon, J.Y. (2017). Cathepsin B \& D and the Survival of Early Embryos in Red Spotted Grouper, Ephinephelus akaara. Development \& Reproduction, 21(4), 457-466. https://doi.org/10.12717/DR.2017.21.4.457

Hashimoto, Y., Kakegawa, H., Narita, Y., Hachiya, Y., Hayakawa, T., Kos, J., Turk, V., \& Katunuma, N. (2001). Significance of cathepsin B accumulation in synovial fluid of rheumatoid arthritis. Biochemical and Biophysical Research Communications, 283(2), 334-339. https://doi.org/10.1006/bbrc.2001.4787

Hook, G., Yu, J., Toneff, T., Kindy, M., \& Hook, V. (2014). Brain pyroglutamate amyloid-beta is produced by cathepsin B and is reduced by the cysteine protease inhibitor E64d, representing a potential Alzheimer's disease therapeutic. Journal of Alzheimers Disease, 41(2), 129149. https://doi.org/10.3233/JAD-131370

Illy, C., Quraishi, O., Wang, J., Purisima, E., Vernet, T., \& Mort, J.S. (1997). Role of the occluding loop in cathepsin B activity. Journal of Biological Chemistry, 272,1197-1202. https://doi.org/10.1074/jbc.272.2.1197

Jing, J., Wu, J., Liu, W., Xiong, S., Ma, W., Zhang, J., Wang, W.M. Gui, J.F., \& Mei J. (2014). Sex-biased miRNAs in gonad and their potential roles for testis development in yellow catfish. PLoS One, 9:e107946.

https://doi.org/10.1371/journal.pone.0107946

Ke, F., Wang, Y., Hong, J., Xu, C., Chen, H., \& Zhou, S.B.(2015). Characterization of MMP-9 gene from a normalized cDNA library of kidney tissue of yellow catfish (Pelteobagrus fulvidraco). Fish \& Shellfish Immunology, 45(2), , 260-267.

https://doi.org/10.1016/j.fsi.2015.04.012

Ke, X., Wang, J., Li, M., Gu, Z., \& Gong, X. (2010). First report of Mucor circinelloides occurring on yellow catfish (Pelteobagrus fulvidraco) from China. Fems Microbiology Letters, 302(2), 144-150. https://doi.org/ 10.1111/j.1574-6968.2009.01841.x

Krupa, J.C., Hasnain, S., Nagler, D.K., Menard, R., \& Mort, J.S. (2002). S2' substrate specificity and the role of His110 and His111 in the exopeptidase activity of human cathepsin B. Biochemical Journal, 361, 613-619. https://doi.org/10.1042/0264-6021:3610613

Langdon, Y.G., Fuentes, R., Zhang, H., Abrams, E.W., Marlow, F.L., \& Mullins, M.C.(2016). Split top: a maternal cathepsin B that regulates dorsoventral patterning and morphogenesis. Development, 143(6), 1016-1028. https://doi.org/10.1242/dev.128900

Lecaille, F., Kaleta, J., \& Bromme, D.(2002). Human and parasitic papain-like cysteine proteases: their role in physiology and pathology and recent developments in inhibitor design. Chemical Reviews, 102(12), 4459-4488. https://doi.org/10.1021/cr0101656

Li, C., Song, L., Tan, F., Su, B., Zhang, D., Zhao, H., \& Peatman, E.(2015). Identification and mucosal expression analysis of cathepsin B in channel catfish (Ictalurus punctatus) following bacterial challenge. Fish \& Shellfish Immunology, 47(2), 751-757. https://doi.org/10.1016/j.fsi.2015.10.028

Li, M., Li, Q., Yang, Z., Hu, G.,Li, T., Chen, X., \& Ao, J. (2014). Identification of cathepsin B from large yellow croaker (Pseudosciaena crocea) and its role in the processing of MHC class II-associated invariant chain. Developmental And Comparative Immunology, 45(2), 313-320. https://doi.org/10.1016/j.dci.2014.03.019

Li, S.H., Li, R., Zhong, H.X., Chen, X.H., Liu, A.P., Yang, J., Hu, Q., Ke, Q.Q., \& Li, M.L.(2017). Immunolocalization of Jian Carp (Cyprinus Carpio Var. Jian) Cathepsin B: Cloning, Expression, Characterization, and Antibody Preparation. Journal of Food Science, 82(5), 1092-1100. https://doi.org/10.1111/1750-3841.13708

Li, X., Meng, X., Kong, J., Luo, K., Luan, S., Cao, B.X., Liu, N., Pang, J.F., \& Shi, X. (2013). Molecular cloning and characterization of a cathepsin B gene from the Chinese shrimp Fenneropenaeus chinensis. Fish \& Shellfish Immunology, 35(5), 1604-1612. https://doi.org/10.1016/j.fsi.2013.09.004

Liu, H., Yin, L.J., Zhang, N., Li, S.H., \& Ma, C.W. (2008). Isolation of cathepsin B from the muscle of silver carp (Hypophthalmichthys molitrix) and comparison of cathepsins $B$ and $L$ actions on surimi gel softening. Food Chemistry, 110(2), 310-318.

https://doi.org/10.1016/j.foodchem.2008.01.068

Liu, W.F., Wen, S.H., Zhan, J.H., Li, Y.S., Shen, J.T., Yang, W.J., Zhou, X.W., \& Liu, K.X. (2015). Treatment with recombinant Trichinella spiralis cathepsin B-like protein ameliorates Intestinal Ischemia/Reperfusion injury in mice by promoting a switch from $M 1$ to $M 2$ macrophages. The Journal of Immunology, 195(1), 317328. https://doi.org/10.4049/jimmunol.1401864

Musil, D., Zucic, D., Turk, D., Engh, R.A., Mayr, I., Huber, R., Popovic, T., Turk, V., Towatari, T., \& Katunuma, N. (1991). The refined 2.15 A X-ray crystal structure of human liver cathepsin $B$ : the structural basis for its specificity. The Embo Journal, 10(9), 2321-2330. https://doi.org/10.1002/j.1460-2075.1991.tb07771.x

Na, J.Y., Song, K., Lee, J.W., Kim, S., \& Kwon, J. (2016). 6Shogaol has anti-amyloidogenic activity and ameliorates Alzheimer's disease via CysLT1R-mediated inhibition of cathepsin B. Biochemical and Biophysica Research Communication, 477(1), 96-102.

https://doi.org/10.1016/j.bbrc.2016.06.026

Norval, M. (2012). Virus-Cell Interactions. In D. Greenwood, R. Slack, \& M. Barer. (Eds.), Medical Microbiology (pp. 8296). Churchill Livingstone press.

Patman, G. (2014). Liver transplantation. Immune responses to 
HCV infection linked to liver transplant tolerance. Nature Reviews Gastroenterology \& Hepatology, 11(8), 454. https://doi.org/10.1038/nrgastro.2014.124

Svara, T., Pogacnik, M., \& Juntes, P. (2010). Distribution and amount of cathepsin B in gentamicin-induced acute kidney injury in rats. Polish Journal Veterinary Science, 13(1), 75-82. PMID: 21077434.

Trabandt, A., Gay, R.E., Fassbender, H.G., \& ,Gay, S. (1991). Cathepsin B in synovial cells at the site of joint destruction in rheumatoid arthritis. Arthritis \& Rheumatism, 34(11), 1444-1451.

https://doi.org/10.1002/art.1780341116

Turk, B., Turk, D., \& Turk, V. (2000). Lysosomal cysteine proteases: more than scavengers. Biochimica et Biophysica Acta, 1477(1-2), 98-111. https://doi.org/10.1016/S0167-4838(99)00263-0

Turk, V., Stoka, V., Vasiljeva, O., Renko, M., Sun, T., Turk, B., \& Turk D. (2012). Cysteine cathepsins: from structure, function and regulation to new frontiers. Biochimica et Biophysica Acta, 1824(1), 68-88.

https://doi.org/10.1016/j.bbapap.2011.10.002

Wang, Y., Ke, F., Ma, J., \& Zhou, S. (2016). A tandem-repeat galectin-9 involved in immune response of yellow catfish, Pelteobagrus fulvidraco, against Aeromonas hydrophila. Fish \& Shellfish Immunology, 51, 153-160. https://doi.org/10.1016/j.fsi.2016.02.018

Wang, Y., Liu, X., Lv, S., Ren, J., \& Ke, F. (2017). Identification and activity of a paralog of cathepsin $S$ from yellow catfish (Pelteobagrus fulvidraco) involved in immune response. Fish \& Shellfish Immunology, 61, 16-23. https://doi.org/10.1016/j.fsi.2016.12.020

Wei, S., Huang, Y., Huang, X., Cai, J., Yan, Y., Guo, C., \& Qin, Q. (2014). Characterization of cathepsin B gene from orange-spotted grouper, Epinephelus coioides involved in SGIV infection. Fish \& Shellfish Immunology, 36(1), 194-205. https://doi.org/10.1016/j.fsi.2013.11.006

Whang, I., De Zoysa, M., Nikapitiya, C., Lee, S., Oh, C., Jung, S.J., Oh, M.J., Choi, C.Y., Yeo, S.Y., Kim, B.S., Kim, S.J., \& Lee, J. (2011). Molecular characterization and expression analysis of Cathepsin B and L cysteine proteases from rock bream (Oplegnathus fasciatus). Fish \& Shellfish Immunology, 30(3), 763-772. https://doi.org/10.1016/j.fsi.2010.12.022

Wu, Q.Q., Xu, M., Yuan, Y., Li, F.F., Yang, Z., Liu, Y., Zhou, M.Q., Bian, Z.Y., Deng, W., Gao, L., Li, H., \& Tang, Q.Z.(2015). Cathepsin $B$ deficiency attenuates cardiac remodeling in response to pressure overload via TNF- $\alpha$ /ASK1/JNK pathway. American Journal of Physiology-Heart and Circulatory Physiology, 308(9), H1143-54. https://doi.org/10.1152/ajpheart.00601.2014

Zhang, F.T., Zhang, Y.B., Chen, Y.D., Zhu, R., Dong, C.W., Li, Y.Y., Zhang,Q.Y., \& Gui, J.F. (2008). Expressional induction of Paralichthys olivaceus cathepsin B gene in response to virus, poly I:C and lipopolysaccharide. Fish \& Shellfish Immunology, 25(5), 542-549. https://doi.org/10.1016/j.fsi.2008.07.018

Zhou, Q., Jin, M., Elmada, Z.C., Liang, X., \& Mai, K. (2015a). Growth, immune response and resistance to Aeromonas hydrophila of juvenile yellow catfish, Pelteobagrus fulvidraco, fed diets with different arginine levels. Aquaculture, 437(1), 84-91. https://doi.org/10.1016/j.aquaculture.2014.11.030

Zhou, Z.J., Qiu, R., \& Zhang, J. (2015b). Molecular characterization of the cathepsin B of turbot (Scophthalmus maximus). Fish Physiology And Biochemistry, 41(2), 473-483. https://doi.org/10.1007/s10695-014-9998-4 